\title{
UMA RELEITURA DO ACESSO À JUSTIÇA NA SOCIEDADE CONTEMPORANEA: A (DES)NECESSIDADE DE TENTATIVA DE AUTOCOMPOSIÇÃO PARA A COMPROVAÇÃO DA EXISTÊNCIA DO INTERESSE DE AGIR
}

\author{
Thiago Ferreira Marcheti \\ Rogério Molica ${ }^{1}$
}

\section{Resumo:}

O objetivo dessa pesquisa é propor uma reinterpretação do acesso à justiça, tendo em vista o estágio que se encontra o Judiciário. Uma das maneiras de se buscar uma melhor efetividade reside no sistema multiportas, no qual Judiciário não seja visto como a única maneira de solucionar conflitos de interesses. No que pese a determinação para se utilizar a mediação e a conciliação em todos os momentos do processo. Propõe-se como solução uma releitura do acesso à justiça, sendo considerado como uma condição para o interesse processual que a parte busque uma das formas alternativas de resolução do conflito

Palavras-chave: acesso a justiça; princípio da efetividade; autocomposição; condições da ação

\section{A REVIEW OF ACCESS TO JUSTICE IN CONTEMPORARY SOCIETY: THE (UN)NEED OF SELF-COMPOSITION ATTEMPT TO PROVE THE EXISTENCE OF THE INTEREST TO ACT}

\begin{abstract}
:
The objective of this research is to propose a reinterpretation of access to justice, considering the stage that the Judiciary is at. One of the ways to seek better effectiveness lies in the multiport system, in which the Judiciary is not seen as the only way to resolve conflicts of interest. Despite the determination to use mediation and conciliation at all times in the process. A reinterpretation of access to justice is proposed as a solution, being considered as a condition for the procedural interest that the party seeks one of the alternative forms of conflict resolution.
\end{abstract}

Keywords: access to justice; principle of effectiveness; self-composition; conditions of action

\section{1) Introdução}

\footnotetext{
${ }^{1}$ Possui graduação em direito pela Universidade de São Paulo (1997), mestrado em Direito Processual pela Universidade de São Paulo (2006) e doutorado em Direito Processual pela Universidade de São Paulo (2010). Fundador e ex-presidente do Centro de Estudos Avançados de Processo (Ceapro). Atualmente é professor visitante da Universidade de São Paulo e professor da Graduação e do programa de Pós Graduação da Universidade de Marília, atuando principalmente nos seguintes temas: novo código de processo civil, fazenda pública em juízo, recursos, meios adequados de solução de controvérsia, direito concorrencial, recuperação judicial e direito falimentar, direito tributário, honorários advocatícios e coisa julgada.
} 
$\mathrm{O}$ direito ao acesso à justiça possui tanto previsão constitucional no artigo $5^{\circ}, \mathrm{XXXV}$ como no artigo $3^{\circ}$ do Código de Processo Civil, os quais possuem a mesma diretriz de impossibilitar que lesão ou até mesmo ameaça a lesão seja afastada de análise jurisdicional.

Em estudo aprofundado sobre o tema Mauro Cappelletti e Bryan Garth apontam a existência de três marcos no que se refere ao acesso à justiça.

O primeiro deles se refere ao ingresso no Poder Judiciário com a diminuição das barreiras econômicas. Esse momento pode ser identificado no Brasil com a estruturação da assistência judiciária e da defensoria pública, bem como na criação dos Juizados Especiais em que não se é exigida a presença de advogado para causas a depender da alçada além de a regra geral prever que as custas processuais somente sejam exigidas quando do início da fase recursal.

O segundo marco se refere às demandas coletivas, o que pode ser evidenciado tanto pela Lei da Ação Civil Pública, como pelas normas previstas no Código de Defesa do Consumidor atinente à atuação em direitos coletivos.

Por sua vez, a terceira se refere ao instrumentalismo do processo e o estímulo aos métodos alternativos de resolução do conflito, o que pode ser evidenciado com a promulgação do novo Código de Processo Civil, o qual se preocupou em simplificar o procedimento focando o processo como um mero meio para se atingir o bem jurídico perseguido bem como determinou logo em seus primeiros artigos, como uma norma fundamental, que compete a todos que de certa forma interfiram na relação processual o estímulo à conciliação e a mediação.

A presença mais significativa de meios como a mediação e a conciliação como técnicas adequadas a solucionar determinados conflitos tem se mostrado cada vez mais necessária, tendo em vista que não é de hoje que se observa um aumento do tempo para resolução dos conflitos e no número de demandas ajuizadas perante o Judiciário não obstante os esforços empreendidos por todo o material humano do tribunal

Esse cenário aponta que a busca pela eficiência, a qual foi erigida expressamente como princípio processual pelo Código de Processo Civil vigente, pode estar na criação de estímulos processuais para que se atinja uma justiça multiportas na qual a tutela jurisdicional deve ser vista como mais um meio para resolver os conflitos, que, inclusive, pode ser o adequado para determinadas demandas em virtude da peculiaridade inerente a cada conflito de interesse. 
A busca pela eficiência, que significa o melhor aproveitamento dos recursos disponíveis para que se atinja o melhor resultado possível, é estudada há tempos pela economia que tem como premissa metodológica básica a ideia de que os recursos são escassos e as necessidades infinitas, sendo assim busca-se através de estudos do comportamento dos agentes econômicos criar um ambiente onde se extrai os melhores resultados esperados pela sociedade.

Nesse sentido, se amparou na aproximação entre o direito e a economia para analisar o processo civil como uma instituição econômica, não bastando a previsão normativa de que se deve estimular a mediação e a conciliação, sendo necessário que se criem verdadeiros estímulos processuais para que o norte legislativo seja de fato atingido.

Uma forma de incentivo proposto seria uma releitura do acesso à justiça com enfoque na análise econômica do direito processual principalmente sob o viés da economia comportamental para que se entenda como condição para que fique materializado o interesse de agir deve se demonstrar de antemão que se buscou a solução alternativa do conflito, seja através da mediação ou da conciliação.

\section{2) O Princípio do Acesso à Justiça na Sociedade Contemporânea}

O conceito de acesso à justiça tem sofrido transformações com o passar do tempo. Em primeiro momento histórico, identificado pelo Estado burguês marcados por ideias do liberalismo clássico o qual pregava a abstinência de atuação estatal como respeito a liberdade dos cidadãos, a efetivação acesso à justiça era visto apenas como a possibilidade de ingresso no Judiciário não dando importância com o que efetivamente ocorria na prática.

Com o surgimento do welfare state, marcado por uma atuação positiva do Estado o qual passa a ter tarefa de efetivar os direitos sociais, o acesso à justiça passa a ser visto como um requisito para um sistema jurídico igualitário, afinal será através da intervenção jurisdicional marcada pela atuação do Estado Juiz que se buscará efetividade aos direitos fundamentais. (CAPPELLETTI, GARTH, 1988)

Modernamente, as técnicas processuais para resolução dos conflitos devem ser encaradas tomando por base a sua função social, que consiste na pacificação dos anseios sociais. Para tanto se exige do processualista que se analise sobre a contribuição de outras ciências como a psicologia e a economia.

Nesse sentido, Mauro Cappelletti e Bryan Garth. 
Os juristas precisam, agora, reconhecer que as técnicas processuais servem a funções sociais; que as cortes não são a única forma de solução de conflitos a ser considerada e que qualquer regulamentação processual, inclusive a criação ou encorajamento de alternativas ao sistemas judiciário formal tem um efeito importante sobre a forma como opera a lei substantiva - com que frequência ela é executada, em benefício de quem e com que impacto social. Uma tarefa básica dos processualistas modernos é expor o impacto substantivo dos vários mecanismos de processamento de litígios. Eles precisam, consequentemente, ampliar sua pesquisa para mais além dos tribunais e utilizar os métodos de análise da sociologia, da política, da psicologia, e da economia, e ademais aprender através de outras culturas. $\mathrm{O}$ "acesso" não é apenas um direito social fundamental, crescentemente reconhecido; ele é, também, necessariamente, o ponto central da moderna processualística. Seu estudo pressupõe um alargamento e aprofundamento dos objetivos e métodos da moderna ciência jurídica. (CAPPELLETTI, GARTH, 1988, p.13)

Os mencionados autores identificam três ondas no que se refere ao enfrentamento dos problemas atinentes ao acesso à justiça.

A primeira delas possui ligação com as barreiras ligadas a desigualdade atinente a população mais carente de recursos financeiros. Como mencionado, segundo a visão clássica, a simples possibilidade de acesso à justiça já bastaria, tendo em vista que se exige do Estado uma posição de abstenção consistente na ausência de interferência nas relações privadas. Nesse sentido, o fato de ser possível o ingresso no Judiciário, mesmo desconsiderando as barreiras sociais existentes, já seria suficiente.

Nessa toada, a primeira onda se preocupa justamente em prestar uma assistência judiciária à população carente se preocupando, justamente, com a igualdade em seu aspecto material, ou seja, equalizando as discrepâncias existentes no plano fático. Podemos apontar como exemplo desse movimento a gratuidade da justiça.

A segunda onda se concentra na proteção dos direitos coletivos. A ciência processual, classicamente, se preocupa em resolver conflitos de interesses entre dois indivíduos ficando, assim, à mercê de enfrentar problemas referente a direitos difusos e coletivos. De acordo com essa onda, passa a se preocupar com a proteção de direitos de toda a coletividade como, por exemplo, a proteção ao meio ambiente, visto que, no que pese a poluição propagada por determinada empresa afetar a vida de toda a humanidade, dificilmente alguém, de maneira individual, buscaria a tutela jurisdicional para sanar o dano perpetuado.

A terceira onda se preocupa em melhorar técnicas processuais para inclusive se evitar litígios, o que a nosso ver, reflete o contraponto com as duas primeiras em que a 
preocupação principal era com o ingresso nesta, o que se preocupa com o modo em que o acesso à justiça ocorrerá.

Nesse sentido, Mauro Cappelletti e Bryan Garth.

$\mathrm{O}$ novo enfoque de acesso à Justiça, no entanto, tem alcance muito mais amplo. Essa "terceira onda" de reforma inclui a advocacia, judicial ou extrajudicial, seja por meio de advogados particulares ou públicos, mas vai além. Ela centra sua atenção no conjunto geral de instituições e mecanismos, pessoas e procedimentos utilizados para processar e mesmo prevenir disputas nas sociedades modernas. (CAPPELLETTI, GARTH, 1988, p.13)

A sociedade moderna, na qual estamos inseridos, é marcada pela rapidez nas relações, o que levou a um aumento considerável no número de conflitos, afinal quanto mais interações sociais, maior o número de conflitos existentes.

Zygmunt Bauman intitula os primórdios do capitalismo como pesado pelo fato do capital, da administração e do trabalho andarem necessariamente juntos. Nessa fase, os modelos econômicos empresariais eram pautados pelo volume e pelo tamanho, sendo assim uma das preocupações para conquista de novos mercados estava marcado pelo avanço das fronteiras físicas e pela baixa rotatividade de mão de obra, o que levava os grandes conglomerados empresariais a buscarem maneiras para que a mão de obra permanecesse vinculada ao capital que a explora pelo maior tempo possível.

Em contrapartida ao capitalismo pesado, o mencionado filósofo polonês identifica, na modernidade, o capitalismo leve marcado pela ruptura com o modelo anterior em que o capital se mantinha fixo. No modelo atual, a principal característica é a fluidez do capital não sendo mais necessário para sua exploração a junção com a administração e trabalho. (BAUMAN, 2001)

Atualmente, podemos identificar o modelo apontado nas grandes empresas que figuram em posição de destaque no cenário econômico uma dissonância entre os elementos capital, administração e trabalho marcando, assim, a presença de uma enorme leveza na exploração e uma maior rapidez no desenvolvimento do capital em virtude do maior número de relações empregadas.

Tomemos como exemplo a Uber, a qual em um modelo clássico decorrente do capitalismo pesado seria comparada com uma grande frotista de transporte público sendo assim necessário a conjugação de uma enorme quantidade de veículos aliado a contratação de um grande número de funcionários para que possa ter o tamanho e a presença econômica que 
tem hoje em dia, ao passo que no capitalismo leve a sua presença em todo o globo terrestre se faz presente sem que possua um único veículo ou mesmo um grande número de motoristas.

Outro exemplo seria o Airbnb, que no capitalismo pesado poderia ser comparado com uma grande rede hoteleira sendo assim necessário para sua expansão mundial a aquisição de novos hotéis ao redor do mundo, quando na modernidade não possui um imóvel sequer bastando que faça a aproximação para que assim se explore o capital e obtenha maiores recursos.

Esses modelos presentes na modernidade têm em comum além separação entre capital, administração e trabalho uma enorme velocidade de escalonamento possibilitando, assim, um maior número de relações comerciais, afinal o incremento do negócio não são necessários os mesmos esforços físicos necessários no capitalismo pesado em que se buscava a conquista de novos mercados através do aumento das fronteiras econômicas com a aquisição de novos ativos a serem explorados.

De maneira reflexa ao aumento das relações temos o aumento considerável dos conflitos demonstrando, assim, cada vez mais latente a necessidade de observarmos mais atentamente como o acesso à justiça é realizado buscando meios para que cada conflito seja resolvido no meio mais adequado para tanto.

Ao observarmos os números do último relatório Justiça em Números divulgado pelo Conselho Nacional de Justiça nos deparamos com dados alarmantes como, por exemplo, o tempo médio para o trâmite em um processo na primeira instância dos Juizados Especiais ser de 1 ano e 7 meses sem contar, ainda, o tempo necessário nas turmas recursais, que é de 1 ano e 2 meses. (CNJ, 2020, p. 47)

O sistema dos juizados especiais, na esteira da primeira onda do acesso à justiça, foi criado para resolver conflitos de baixa complexidade como, por exemplo, problemas atinentes ao direito do consumidor, dessa forma o objetivo do legislador era justamente a entrega da prestação jurisdicional de maneira mais célere atendendo, assim, o postulado constitucional da razoável duração do processo, afinal não seria crível demorar um lapso temporal considerável para resolver conflitos de baixa complexidade.

Entretanto, os números apontam cenário diverso, afinal uma demanda simples que deveria ser resolvida rapidamente acaba demorando quase 3 (três) anos só para ter uma solução no processo de conhecimento sem contar, ainda, o tempo na fase de execução quando se fizer necessário. 
Por outro lado, se olharmos para os índices de produtividade veremos que, não obstante os resultados apontados, veremos que o trabalho despendido pelo corpo humano do tribunal tem sido satisfatório apresentando altos índices de produtividade. Vejamos como, exemplo, o Tribunal de Justiça de São Paulo em que o índice na $2^{\mathrm{a}}$ instância foi de $100 \%$ e na primeira instância de $89 \%$.

Acrescente-se, ainda, que parcela considerável do Produto Interno Bruto já é gasto com o Poder Judiciário e se pensarmos em uma estrutura para atender os anseios do mundo moderno seria necessário gastos ainda mais expressivo, o que seria um contrassenso se levarmos em conta que existem outros gastos em saúde e educação que se fazem necessários em virtude do estágio em que se encontra a sociedade brasileira.

Os números apontam que a visão paternalista incutida na sociedade em relação ao Poder Judiciário deve ser modificada, pois, diante da fluidez e leveza das relações presente na sociedade moderna que acabam resultando no maior número de conflitos, se faz necessário que a resolução de conflitos também quebre paradigmas e correntes presentes atinentes ao modelo do capitalismo pesado adequando-se, assim, ao capitalismo leve identificado por Zygmunt Bauman.

Vejamos a lição de Gisele Lemke

\begin{abstract}
Note-se que essa é uma grande alteração da abordagem do problema, uma vez que, ao invés de se tratar da questão sob o prisma da oferta de serviços judiciais, passa-se a tratar do problema sob o prisma da demanda dos serviços judiciais. Vale dizer, ao invés de serem verificados meios apenas de se ampliar a oferta dos serviços judiciais e de se resolver o problema do grande estoque de processos atualmente existente, passa-se a verificar se a demanda não estaria exagerada, ou seja, se o acesso à Justiça não estaria sendo confundido com o acesso ao Judiciário, causando o estrangulamento deste. (LEMKE, 2020, n.p)
\end{abstract}

O acesso à justiça não pode ser equivalente ao acesso ao judiciário, este deve ser visto como um dos meios para resolução dos conflitos, mas não o único e nem o principal. Os conflitos, antes da intervenção do jurisdicional através da figura do Estado Juiz, deve perpassar pela busca autocompositiva. (TARTUCE, 2020)

\title{
3) Mediação e Conciliação e Justiça Multiportas
}

O acesso à justiça foi detidamente estudado na década de 70 pelos doutrinadores Mauro Cappelletti e Bryant Garth, sendo apresentado diversos obstáculos para sua implementação, que foi identificado através das ondas renovatórias. O primeiro deles se refere 
aos custos decorrentes ao ingresso, sendo, assim, previsto na Constituição Federal, como direito fundamental, em seu artigo $5^{\circ}$, LXXIV à prestação de assistência judiciária gratuita por parte do Estado aos necessitados.

Igualmente na toada de possibilitar o amplo ingresso ao Poder Judiciário, o artigo 98, I da carta cidadã prevê a criação de juizados especiais destinados a julgamento de causas de menor complexidade. Nesse sentido, atualmente a legislação que rege esta temática é a Lei 9.099/95, a qual prevê, em seu artigo 54, a dispensa no pagamento das custas e emolumentos em primeiro grau de jurisdição.

O amplo acesso ao poder judiciário resultou em um aumento considerável no número de demandas ajuizadas, o que impactou de maneira significativa no tempo de tramitação, influenciando, assim, na entrega da prestação jurisdicional. Passou-se, então, a defender que o acesso à justiça não seria satisfeito com o simples ingresso no Poder Judiciário, sendo assim imperioso observar como e em qual momento e de qual modo o direito foi efetivamente tutelado.

Todo esse cenário fez eclodir no movimento que resultou na inclusão do princípio da razoável duração do processo como direito fundamental, afinal de nada adiantaria garantir o acesso ao judiciário sem se preocupar com a maneira como o serviço jurisdicional é prestado. (FIGUEIREDO, 2020)

Como forma de instrumentalizar o postulado a razoável duração do processo, foi editada pelo Conselho Nacional de Justiça a Resolução 125, em 29 de novembro de 2010, a qual dentre as razões para sua criação está a necessidade de diminuir a excessiva judicialização do conflito, buscando, com isso, que se modifique o paradigma referente a cultura da sentença instaurado em terras brasilis para a cultura da pacificação social. Esse objetivo fica latente quando nos deparamos com a redação do artigo $2^{\circ}$ o qual deixa claro quais são os escopos da aludida resolução.

Em sintonia com a Resolução 125 foi promulgada a Lei 13.140/2015, a qual dispõe sobre a mediação entre particulares como meio de solução de controvérsias e sobre a autocomposição de conflitos no âmbito da administração pública.

Houve, ainda, o advento do Código de Processo Civil, através da Lei 13.105/2015, o qual prevê, em seu artigo $3^{\circ}, \S 3^{\circ}$, como norma fundamental, o dever de todos aqueles que integram a relação jurídica processual de estímulo aos meios consensuais de resolução dos conflitos. 
Essas normas processuais no ordenamento jurídico brasileiro criaram um microssistema de meios consensuais de composição de conflitos demonstrando, assim, a importância que o legislador tem dado às formas diversas, que não seja através da tutela jurisdicional, de resolução de conflitos. (TARTUCE, 2018)

A mediação, na dicção legal do artigo $1^{\circ}$ da Lei 13.140/2015, é conceituada como a atividade na qual um terceiro imparcial, não possuindo poder decisório, auxilia, estimula e até mesmo desenvolve soluções consensuais. Nesta modalidade, o mediador terá papel crucial para que o diálogo se restabeleça possibilitando, assim, que as partes possam pôr fim ao litígio sem que se faça necessário a imposição de uma decisão. Por sua vez, o conciliador atuará preferencialmente nas causas em que não possua vínculo anterior com as partes e poderá sugerir soluções. (TARTUCE, 2020)

O Código de Processo Civil, atento ao postulado do estímulo à conciliação e mediação, modificou o procedimento comum ordinário no sentido de que a citação do réu será para o comparecimento em uma audiência de conciliação e mediação, diferentemente da sistemática do diploma processual revogado que facultava ao réu apresentar sua defesa.

O diploma processual vigente, quedou-se, ao menos de maneira expressa, em apresentar qualquer exigência prévia de conciliação prévia ao ajuizamento da ação. Pela dicção literal do diploma processual, apenas, em hipóteses excepcionais, quando, por exemplo, ambas as partes não desejem a sua realização ou quando o direito em discussão não admitir a autocomposição, é que será dispensada a audiência de conciliação. (CAZELLI; FERRO, 2020)

No que pese, a nosso ver ser louvável a tentativa do legislador em exigir que o processo se inicie com uma sessão conciliatória, essa situação, em muitos casos, na praxis forense tem se mostrado inócua não sendo raro nos depararmos com a dispensa de realização de conciliação sob fundamento de alongamento de pauta ou dificuldades de cunho estrutural presente na realidade de determinada comarca.

Há, ainda, fortes críticas ao momento escolhido para sua realização, tendo em vista que a audiência é realizada sem que as partes tenham a plena ciência sobre quais os pontos controvertidos na lide, afinal, a audiência é realizada antes mesmo da apresentação de defesa pelo réu o que leva a uma assimetria informacional e como consequência pode resultar em 
otimismo exacerbado dificultado, desse modo, que a autocomposição seja atingida. (WOLKART, 2020).

Portanto, apesar do Código de Processo Civil, prever de maneira expressa em seu artigo $3^{\circ}, \S 3^{\circ}$, o dever de estímulo à mediação e conciliação a todos aqueles que integram a relação jurídica processual, mesmo após 5 anos de sua vigência os índices de conciliação não têm se mostrado satisfatórios, o que, a nosso ver, está intimamente ligado à ausência de estímulos processuais efetivos, tendo o legislador se limitado em definir de maneira axiomática o estímulo às formas alternativas de resolução do conflito.

\section{4) Estímulos processuais para conciliação e mediação}

O Código de Processo Civil, prevê em seu artigo $6^{\circ}$, o princípio da cooperação como uma norma fundamental estruturante de todo o ordenamento jurídico processual vigente. Entretanto, ao nos depararmos com a sistemática processual vigente, não notamos um ambiente cooperativo, ao contrário, nos deparamos com um ambiente de extrema beligerância e de pouca cooperação entre os atores da relação jurídica processual.

Atualmente, a doutrina processual, conceitua processo como um feixe de relações jurídicas, na qual há uma constante interação entre os seus integrantes. As normas processuais passam a ter duas funções, quais sejam, prevenir comportamentos tido como indesejados e estimular a prática dos que são esperados. (ABREU, 2021)

A teoria geral do processo pode ser conceituada como uma disciplina que busca descrever e explicar os institutos fundamentais para todo e qualquer sistema processual, quais sejam ação, jurisdição e processo. De todo modo, no que pese o direito consistir em um mecanismo formal capaz de possibilitar a vida em sociedade e a teoria geral do processo buscar justamente se debruçar sobre os institutos que dão ensejo a qualquer ambiente processual, não encontramos na ciência jurídica maiores preocupações de como se dará o comportamento humano diante de uma determinada norma.

Nesse sentido, a ciência econômica pode contribuir de maneira substancial, afinal, trata-se da área do conhecimento em que se pauta no estudo do comportamento humano diante de um ambiente de escassez de recursos. A economia parte da premissa básica de que vivemos em um ambiente em que as necessidades são infinitas e os recursos finitos, sendo assim para que se busque o bem-estar da coletividade é necessário criar estímulos para que o 
comportamento individual não prejudique o nível de eficiência esperado. (JUNIOR GICO, 2020)

Vejamos a lição de Ivo Teixeira Gico Junior:

O direito é, de uma perspectiva mais objetiva, a arte de regular o comportamento humano. A economia, por sua vez, é a ciência que estudo como o ser humano toma decisões e se comporta em um mundo de recursos escassos e suas consequências. A análise econômica do direito, portanto, é o campo de conhecimento humano que tem por objetivo empregar os variados ferramentais teóricos e empíricos econômicos e das ciências afins para expandir a compreensão e o alcance do direito e aperfeiçoar o desenvolvimento, a aplicação e a avaliação de normas jurídicas, principalmente com relação às suas consequências (JUNIOR GICO, 2010, p. 8)

Essa aproximação entre a econômica e o direito tem o condão de possibilitar ao jurista o manejo de ferramentas capazes de identificar quais seriam consequências de determinada norma e quais são os incentivos por ela criados de modo que se busque um aprimoramento das regras jurídicas e do papel do direito na busca do bem-estar social e da máxima eficiência.

A crise vivenciada pelo Judiciário não é recente, há muito que o senso comum qualifica a prestação do serviço jurisdicional é tido como custoso, moroso e ineficiente não atingindo, desse modo, os postulados da eficiência e da duração razoável do processo. Para se chegar a uma possível solução é necessário, de antemão, que se observe quais seriam os motivos que levam alguém a litigar, ou seja, quais seriam os estímulos que impulsionam o comportamento de um determinado cidadão a buscar a tutela jurisdicional.

Inicialmente, quando se pensa no acesso à justiça sob uma perspectiva eminentemente jurídica desprovida das consequências práticas, tem-se que quanto mais as pessoas puderem ter acesso ao Poder Judiciário mais se estará efetivando este direito fundamental, afinal, com isso, se possibilitará que um maior número de pessoas tenha acesso à tutela jurisdicional.

Entretanto, sob uma perspectiva econômica, tem-se que os agentes racionais, quando instados a tomar uma decisão, acabam se baseando em seu aspecto individual e particular desconsiderando os efeitos reflexos de sua escolha. Nessa toada, conclui-se que nem toda pretensão conduzirá à busca da eficiência, tendo em vista que a prestação do serviço pelo Poder Judiciário tem um custo, o qual, necessariamente deve ser superior aos resultados alcançados. 
Acrescente-se que o resultado dessa equação não deve ser visto sob a perspectiva apenas do caso concreto posto em discussão. É necessário que se observe as consequências sociais da intervenção estatal. Exemplificando, quando uma sentença é proferida atribuindo a responsabilidade pela prática de determinada conduta tem, inevitavelmente, como consequência, criar um estímulo à precaução tanto na parte que fora condenada quanto em terceiros que tiveram ciência acerca da mencionada decisão.

Entretanto, quando o autor decide ajuizar uma ação sua decisão leva em conta apenas a sua parcela da equação, não considerando, assim, para tomada de sua decisão os custos que a parte adversa terá e menos, ainda, nos custos judiciais. (FUX, 2020)

Outro dado importante, é a conclusão advinda da economia comportamental de que o ser humano é naturalmente otimista, sendo assim em um ambiente em que as informações são deficitárias a tendência natural é que surja o sentimento de que o resultado da empreitada será positivo. Este viés aliado a instabilidade das decisões judiciais e ao fato de que sistema de custas do Poder Judiciário é baixo se considerarmos o valor da pretensão apresentada, sem contar, ainda, na possibilidade de isenção acaba por se estimular o ajuizamento na contramão do desejado se afastando, assim, do bem-estar social.

$\mathrm{Na}$ economia, mais especificamente sob a perspectiva da microeconomia, tem-se o conceito de bem públicos, o qual é definido como aquele que se caracteriza por ser não excludente e não concorrente, o que significa que não se pode excluir determinada pessoa de usufruí-lo e a sua utilização não importa em diminuição da quantidade.

Ao analisarmos a prestação de serviços jurisdicionais podemos concebê-los como um bem público sob a ótica econômica, afinal, todo aquele que deseje procurar o Poder Judiciário poderá assim proceder sem que encontre maiores dificuldades para tanto e o ajuizamento de uma ação não resultará em impacto para que outros também sigam o mesmo caminho.

Essa característica do serviço jurisdicional quando somada à perspectiva individualista têm o enorme potencial de caminhar para a chamada tragédia dos comuns, em que "os recursos comuns (bens comuns) tendem a ser explorados em níveis acima do desejável do ponto de vista social, gerando uma tendência de esgotamento. (o que seria a tragédia)" (WOLKART, 2020, p. 87)

Uma possível solução para esse cenário seria através da previsão de regras jurídicas que busque internalizar os custos sociais decorrente da utilização do serviço jurisdicional, o que poderia ser realizado, por exemplo, com o aumento das taxas judiciárias, uma análise 
mais apurada sobre as consequências do ajuizamento de lides temerárias, repressão a comportamentos ímprobos por partes de atores processuais. Outra ótica de possível solução está em criar incentivos para comportamentos que vá ao encontro das diretrizes do sistema processual, o qual apresenta como uma solução para esse impasse na entrega da prestação da tutela jurisdicional o comportamento cooperativo das partes.

É justamente neste último aspecto que se propõe uma releitura do princípio do acesso à justiça, mais especificamente sob a ótica do interesse de agir, criando, o que nas palavras de Rodolfo de Camargo Mancuso seriam condicionantes ao exercício do direito de ação. O mencionado autor propõe como solução a crise que se instalou no poder judiciário uma releitura ao princípio do acesso à justiça de maneira ampla, irrestrita e incondicionada criando, assim, condicionantes para que se possa ingressar no Poder Judiciário exigindo que o jurisdicionado busque de antemão a solução autocompositiva, seja através da mediação ou da conciliação. Nessa toada, o acesso ao judiciário estaria condicionado ao insucesso da fase conciliatória prévia ao ajuizamento da demanda ou nos casos de urgência. (MANCUSO, 2020)

Propostas, como estas, se mostraram satisfatórias em países como a Colômbia, que em uma recente alteração em sua legislação somente permite o ingresso no Poder Judiciário quando a conciliação não se mostra possível, seja porque mesmo com o restabelecimento do diálogo não foi possível se chegar a um consenso seja por ineficiência do sistema autocompositivo decorrente da mora para realização da sessão conciliatória ou, ainda, em virtude de urgência. (CAZELLI, FERRO, 2020)

Vinicius Ribeiro Cazelli e Ricardo Rage Ferro

Em outras palavras, consideradas as condições da ação in status assertionis, faz-se necessária a demonstração por parte do autor de que o uso da máquina do judiciário dá-se em decorrência de situação imprescindível, em relação a qual não houve possibilidade, seja por conta do tempo, seja pela urgência, seja por simples fata de acordo, de solução extrajudicial, previamente ao aforamento da demanda.

Neste sentido, uma necessária mudança de postura do judiciário, a interpretar a cláusula de inafastabilidade do poder judiciário não como uma garantia a abarcar toda e qualquer demanda, mas sim e somente aquelas não solucionadas previamente pelas partes na esfera extrajudicial (seja pela falta de acordo, seja pela impossibilidade fática ou jurídica de solução) (CAZELLI, FERRO, 2020, p. 406) 
Para Isabela Werneck, em sentido contrário ao posicionamento supratranscrito, antes de condicionar o acesso ao judiciário a tentativa conciliatória deve-se preocupar com a qualidade dos acordos que são firmados e como o serviço é prestado na sessão de conciliação e mediação sob pena de somente criar mais um entrave para que a parte tenha de fato sua contenda analisada pelo Judiciário.

\begin{abstract}
Sabe-se que o conceito de "acesso à justiça deixou de ser entendido apenas em seu aspecto formal há muito tempo. A típica leitura do Estado Liberal, de mero ingresso no Poder Judiciário, se revelou insuficiente e sofreu desde então uma série de mudanças, o que também se estende aos métodos adequados de resolução de controvérsias. Em se tratando de uma iniciativa estatal, de nada adianta garantir a sua existência, obrigar a sua utilização e, ainda, condicioná-la ao acesso ao Poder Judiciário, sem se preocupar com a qualidade dos acordos lá firmados.
\end{abstract}

Gisele Lemke se posiciona nesse mesmo sentido alertando para a possibilidade da fase conciliatória resultar em apenas mais uma fase burocrática.

\begin{abstract}
Entretanto, para que essa medida funcione, é preciso cuidado para que a conciliação não seja transformada em mera etapa burocrática para se chegar à fase judicial, o que, dado o atuar econômico do ser humano, no sentido atribuído ao termo pela corrente Law and Economics,(17) deve ser feito por meio do desestímulo ao ajuizamento de ações judiciais, tornando-as suficientemente onerosas (mormente para a parte que perder a demanda) a ponto de não ser interessante recorrer ao Poder Judiciário, a não ser após realmente esgotados todos os demais meios para a solução do litígio e quando a lide seja suficientemente valiosa (seja do ponto de vista econômico, seja do ponto de vista moral) a justificar a atuação (sempre bastante onerosa em termos de orçamento público) do Poder Judiciário.
\end{abstract}

Fernanda Tartuce acrescenta, ainda, que a conciliação deve ser voluntária, sendo assim um contrassenso que se obrigue às partes a sua participação como momento prévio ao ajuizamento da ação. (TARTUCE, 2018)

No âmbito jurisprudencial, os tribunais de segunda instância têm se posicionado pela impossibilidade de condicionar o exercício do direito de ação a comprovação de prévia tentativa de conciliação. Podemos citar, como exemplo, decisão proferida pelo $19^{a}$ Câmara de Direito Privado do Tribunal de Justiça do Estado de São Paulo, nos autos do processo 2224837-09.2020.8.26.0000 o qual reformou uma decisão proferida por um magistrado de primeiro grau que condicionou a comprovação de prévia tentativa conciliatória ao deferimento da petição inicial, uma vez que segundo seu entendimento haveria violação ao princípio do acesso à justiça. 
Por sua vez, o Supremo Tribunal Federal recentemente entendeu como necessário o prévio requerimento na via administrativa para que o segurado pudesse se valer do judiciário para requerer benefício de natureza previdenciária fixando a tese de número 350 .

\begin{abstract}
I - A concessão de benefícios previdenciários depende de requerimento do interessado, não se caracterizando ameaça ou lesão a direito antes de sua apreciação e indeferimento pelo INSS, ou se excedido o prazo legal para sua análise. É bem de ver, no entanto, que a exigência de prévio requerimento não se confunde com o exaurimento das vias administrativas; II - A exigência de prévio requerimento administrativo não deve prevalecer quando o entendimento da Administração for notória e reiteradamente contrário à postulação do segurado; III - Na hipótese de pretensão de revisão, restabelecimento ou manutenção de benefício anteriormente concedido, considerando que o INSS tem o dever legal de conceder a prestação mais vantajosa possível, o pedido poderá ser formulado diretamente em juízo salvo se depender da análise de matéria de fato ainda não levada ao conhecimento da Administração -, uma vez que, nesses casos, a conduta do INSS já configura o não acolhimento ao menos tácito da pretensão; IV - Nas ações ajuizadas antes da conclusão do julgamento do RE 631.240/MG (03/09/2014) que não tenham sido instruídas por prova do prévio requerimento administrativo, nas hipóteses em que exigível, será observado o seguinte: (a) caso a ação tenha sido ajuizada no âmbito de Juizado Itinerante, a ausência de anterior pedido administrativo não deverá implicar a extinção do feito; (b) caso o INSS já tenha apresentado contestação de mérito, está caracterizado o interesse em agir pela resistência à pretensão; e (c) as demais ações que não se enquadrem nos itens (a) e (b) serão sobrestadas e baixadas ao juiz de primeiro grau, que deverá intimar o autor a dar entrada no pedido administrativo em até 30 dias, sob pena de extinção do processo por falta de interesse em agir. Comprovada a postulação administrativa, o juiz intimará o INSS para se manifestar acerca do pedido em até 90 dias. Se o pedido for acolhido administrativamente ou não puder ter o seu mérito analisado devido a razões imputáveis ao próprio requerente, extingue-se a ação. Do contrário, estará caracterizado o interesse em agir e o feito deverá prosseguir; $\mathrm{V}-\mathrm{Em}$ todos os casos acima - itens (a), (b) e (c) -, tanto a análise administrativa quanto a judicial deverão levar em conta a data do início da ação como data de entrada do requerimento, para todos os efeitos legais.

(RE 631.240)
\end{abstract}

Este posicionamento recente do pretório excelso demonstra uma mudança de paradigma, tendo em vista que quando instado a se manifestar quanto à constitucionalidade da comissão de conciliação prévia na sistemática trabalhista pautou-se pela contrariedade com o texto da carta magna. Segundo a diretriz literal do texto da Consolidação das Leis do Trabalho se exigia que o trabalhador, antes do ingresso perante o judiciário, deveria buscar a conciliação, sendo exigido que com a inicial se a inexistência de sua instituição, ausência de acordo ou mesmo falha decorrente da mora para se realizar a sessão conciliatória.

A nosso ver, se confrontarmos os dois posicionamentos do Supremo Tribunal Federal é possível verificar uma mudança no entendimento, já que inicialmente o 
entendimento era no sentido de que não se poderia criar qualquer condicionante para o ingresso no Judiciário e, atualmente, já se exige, ao menos no âmbito previdenciário, que se apresente o prévio requerimento como condição para o exercício válido do direito de ação.

\section{5) Conclusão}

Ao nos deparamos com os números relativos à prestação dos serviços pelo Poder Judiciário fica evidenciado uma demora para resolução dos conflitos postos para solução. Tudo isso, apesar dos esforços despendidos para que se entregue a tutela jurisdicional em tempo razoável, em consonância com os ditames previstos tanto em tratados internacionais como na Constituição Federal e no Código de Processo Civil.

A preocupação com o tempo de duração das demandas judiciais foi um dos motivos que levou a promulgação do Código de Processo Civil, em 2015, o qual teve como uma das promessas abreviar o tempo de duração das demandas judiciais mediante o manejo de técnicas processuais, dentre as quais está a mudança de paradigma de um processo com índole adversarial para cooperativo.

Nessa toada, foi previsto como norma fundamental, o princípio da cooperação, impondo a todo aquele que integre a relação processual o dever de cooperar de modo que se obtenha a entrega da tutela jurisdicional no menor tempo possível, incluindo, nesse aspecto, a atividade satisfativa. De igual modo, também foi prevista, a necessidade de se estimular, em todas as fases processuais, a conciliação e a mediação.

Entretanto, não obstante os ditames legais previstos, ainda são baixos os índices de resolução através da autocomposição, ainda mais se compararmos com os números apresentados em países com o sistema jurídico pautado na common law em que os casos que são efetivamente enfrentados pelo Poder Judiciário através de uma decisão de mérito são tidos como excepcionais.

Apesar das normas processuais preverem de maneira axiológica a necessidade de se observar a cooperação e de se estimular a autocomposição, seja através da mediação ou da conciliação, não se mostra presente no sistema processual a existência de estímulos para que as diretrizes traçadas sejam efetivamente aplicadas.

Dessa forma, como a economia é a ciência que estuda o comportamento humano diante de recursos escassos, pautamos nosso estudo na análise econômica do direito buscando analisar o processo civil como uma instituição econômica, em que é possível através de 
estímulos criados pela legislação direcionar as ações dos agentes econômicos ao caminho da eficiência comum.

Diante das premissas fixadas, propomos uma releitura do princípio constitucional do acesso à justiça, pois não devemos nos preocupar somente com o ingresso no Poder Judiciário, mas sim também como a prestação da tutela jurisdicional é efetivada. Atualmente o sentimento comum é de que o serviço jurisdicional é caro e ineficiente, visto que quando o cidadão dele necessita se vê diante de vários entraves, dentre eles, a demora para que uma resposta do Estado seja dada.

A solução para essa problemática, ao nosso ver, não está no incremento ao orçamento, o qual nos patamares atuais, já é responsável por parcela considerável do Produto Interno Bruto, ainda mais se compararmos com serviços mais essenciais a toda população como a saúde e a segurança, por exemplo.

Devemos nos preocupar em como criar estímulos para se modificar o paradigma estabelecido, sendo assim observado o ideal cooperativo e não adversarial. Um bom caminho, ainda que inicial, seria realmente se atribuir a tutela jurisdicional como a última ratio exigindo daquela que a busque a comprovação, ao menos da tentativa de solução pacífica do conflito sob pena de não restar caracterizado o interesse processual.

Já podemos observar uma mudança de entendimento na jurisprudência pátria, tendo como leading case o entendimento consolidado no Supremo Tribunal Federal exigindo, como regra geral, que em demandas previdenciárias o autor comprove que solicitou o benefício na esfera administrativa para somente após buscar a interferência judicial.

O mencionado entendimento tende a evitar que o Judiciário se debruce sobre problemas que poderiam ser solucionados de maneira mais simplificada, breve e menos custosa na seara administrativa.

Situações semelhantes podem trazer benefícios para as mais diversas áreas do direito, como, por exemplo, a consumerista, visto que muitos problemas que são levados ao Judiciário tem a aptidão de serem solucionados extrajudicialmente através do auxílio de ferramentas digitais como, por exemplo, o consumidor.gov ou mesmo através de uma mediação realizada no âmbito da Fundação PROCON sem contar, ainda, a possibilidade do auxílio por câmaras privadas.

A exigência da tentativa de solução pacífica se coaduna com a preocupação com o coletivo, afinal de acordo com a sistemática atual a preocupação é puramente individualista 
visto que concentra-se no desejo puramente individual de cada parte de procurar ou não o Poder Judiciário deixando de lado a análise do aspecto coletivo, afinal, o número dos processos ajuizados são alarmantes.

Portanto, para que se atinja o acesso à justiça em seu aspecto material, ou seja, para que se além do ingresso também se preocupe com a qualidade do serviço prestado, se faz necessário que se modifique paradigmas criando, assim, condicionantes ao exercício do direito de ação, sob pena de cada vez nos depararmos com um Judiciário assoberbado e ineficiente vilipendiando, assim, a segurança jurídica. 


\section{REFERÊNCIAS}

ABREU, Rafael, Sirangelo de. Incentivos Processuais: economia comportamental e nudges no Processo Civil. São Paulo: Thomson Reuter Brasil, 2020

BAUMAN, Zygmunt. Modernidade Líquida. Rio de Janeiro: |Zahar, 2001

CAPPELleTti, Mauro; GARTH, Bryan. Acesso à Justiça. Porto Alegre: Sérgio Antonio Fabris Editor, 1988

FIGUEIREDO, Bianca Fernandes. Consumidor.gov.br: a exigência de utilização da plataforma digital de solução adequada de conflitos antes do ajuizamento de ação de consumo como fator de eficiência do Poder Judiciário, à luz da análise econômica do direito. Revista CNJ. Brasília, 4, n. 1, p. 17-36, jan/jul 2020. Disponível em: https://www.cnj.jus.br/ojs/index.php/revista-cnj/article/view/98. Acesso em: 24 set. 2020.

GICO JUNIOR, Ivo Teixeira. Metodologia e Epistemologia da Análise Econômica do Direito. Economic Analysis of Law Review, V. 1, no 1, p. 7-32, Jan-Jun, 2010

GICO JUNIOR, Ivo Teixeira. Análise Econômica do Processo Civil. Indaiatuba, SP : Editora Foco, 2020

LEMKE, Gisele. O congestionamento do Poder Judiciário: um breve estudo sob o ponto de vista da demanda dos serviços judiciais. Revista de Doutrina da $4^{\text {a }}$ Região. Porto Alegre, n. 58, fev. 2014. Disponível em: <https://revistadoutrina.trf4.jus.br/artigos/edicao058/Gisele Lemke.html> Acesso em: 24 set. 2020.

MANCUSO, Rodolfo de Camargo. Acesso à justiça: condicionantes legítimas e ilegítimas. São Paulo: RT, 2011. 
PARO, Giácomo. et al. On-line Dispute Resolution (ODR) e o interesse processual. In: LUCON et al. Direito, Processo e Tecnologia. São Paulo: Revista dos Tribunais, 2020. Disponível em: https://proview.thomsonreuters.com/launchapp/title/rt/monografias/235813054/v1/page/III. Acesso em: 22 set. 2020

TARTUCE, Fernanda. Mediação de conflitos: proposta de emenda constitucional e tentativas consensuais prévias à jurisdição. Revista Magister de Direito Civil e Processo Civil. Brasília, v. 14, n. 82, p. 5-21, jan./fev. 2018. Disponível em: https://www.tjdft.jus.br/institucional/biblioteca/conteudo-revistas-juridicas/revistamagisterde-direito-civil-e-processual-civil/2018-v-14-n-82-jan-fev. Acesso em: 17 set. 2020.

TARTUCE, Fernanda; DA COSTA, Suzane Henrique. Acesso à Justiça, interesse processual e valores módicos. Disponível em: https://www.migalhas.com.br/depeso/311789/acesso-a-justica--interesse-processual-evalores-modicos

VASCONCELOS, Ronaldo; CARNAÚBA, César Augusto Martins. Custos de transação do processo e Online Dispute Resolution: um sistema multiportas 4.0 economicamente eficiente. In: LUCON et al. Direito, Processo e Tecnologia. São Paulo: Revista dos Tribunais, 2020. Disponível em: https://proview.thomsonreuters.com/launchapp/title/rt/monografias/235813054/v1/page/III. Acesso em: 22 set. 2020

VASCONCELOS, Andre Roque; DELLORE, Luiz, GAJARDONI, Fernando da Fonseca, MACHADO, Marcelo Pacheco; JUNIOR, Zulmar Duarte de Olveira. Releitura do princípio do acesso à Justiça: A necessidade de prévio requerimento e o uso da plataforma consumidor.gov.br. Disponível em: https://www.migalhas.com.br/coluna/tendencias-doprocesso-civil/304544/releitura-do-principio-do-acesso-a-justica--a-necessidade-de-previorequerimento-e-o-uso-da-plataforma-consumidor-gov-br Acesso: 01/05/2021 
WERNEK, Isadora. Online Dispute Resolution (ODR) e a (des) Necessidade de Formulação de Reclamação Prévia dos Consumidores junto às Plataformas Virtuais para configuração do Interesse de Agir. in Inteligência Artificial e Direito Processual 